\title{
Primer on the Rheumatic Diseases
}

THIRTEENTH EDITION 



\section{Primer on the Rheumatic Diseases}

THIRTEENTH EDITION

Edited by

JoHN H. KLIPPEL, MD

John H. Stone, MD, MPH

Leslie J. Crofford, MD

Patience H. White, MD, MA

焦 Springer 
John H. Klippel, MD

President and CEO

Arthritis Foundation

Atlanta, GA, USA

Leslie J. Crofford, MD

Gloria W. Singletary Professor of Internal Medicine

Chief, Division of Rheumatology \&

Women's Health

University of Kentucky

Lexington, KY, USA
John H. Stone, MD, MPH

Associate Physician

Massachusetts General Hospital

Deputy Editor for Rheumatology

UpToDate

Boston, MA, USA

Patience H. White, MD, MA

Chief Public Health Officer

Arthritis Foundation

Atlanta, GA, USA

Library of Congress Control Number: 2007925709

ISBN: 978-0-387-35664-8

Printed on acid-free paper

(C) Springer Science+Business Media, LLC. 2008

All rights reserved. This work may not be translated or copied in whole or in part without the written permission of the publisher (Springer Science+Business Media, LLC, 233 Spring Street, New York, NY 10013, USA), except for brief excerpts in connection with reviews or scholarly analysis. Use in connection with form of information storage and retrieval, electronic adaptation, computer software, or by similar or dissimilar methodology now known or hereafter developed is forbidden.

The use in this publication of trade names, trademarks, service marks, and similar terms, even if they are not identified as such, is not to be taken as an expression of opinion as to whether or not they are subject to proprietary rights.

While the advice and information in this book are believed to be true and accurate at the date of going to press, neither the authors nor the editors nor the publisher can accept any legal responsibility for any errors or omissions that may be made. The publisher makes no warranty, express or implied, with respect to the material contained herein.

987654321

springer.com 
The 13th edition of the Primer on the Rheumatic Diseases is an extraordinary handbook for clinical care. The Primer will educate trainees, update established clinicians, and help health care providers from all walks of the profession provide better care for patients with arthritis and rheumatic diseases.

In achieving these purposes, the Primer continues a tradition of excellence dating back more than 70 years. The Primer and its precursors have served as a major learning tool for medical students, house officers, fellows, and allied health professionals since 1934, when the early publications of the American Committee for the Control of Rheumatism included the Primer on Rheumatism: Chronic Arthritis in 1934. Since that work, which consisted of a 52-page brochure, the Primer has evolved into a reference guide of nearly 90 chapters and 4 appendices.

The Primer is designed to provide up-to-date information about the major clinical syndromes seen by primary care physicians, rheumatologists, orthopedic surgeons, as well as physician assistants, nurse practitioners, physical and occupational therapists, and allied health professionals whose expertise contributes to patient care. Emphasis on the evaluation of the patient, the physical examination including musculoskeletal signs and symptoms, laboratory and imaging evaluations, and current and novel therapeutic approaches are essential for all who work in this field. Arthritis and other rheumatic diseases, which affect more than 46 million Americans (including 300,000 children), remain a leading cause of disability and the most common chronic illness in the United States.

I congratulate the editors on their superb work. In addition, the multiple contributors - many of whom are members of the American College of Rheumatologyshould be thanked for their scholarly contributions to the Primer. Rheumatology has never been more exciting than it is today, and there is no doubt that the 13th edition of the Primer reflects this. I join clinicians and patients alike in thanking the Arthritis Foundation for the continuing achievements of this book.

Michael E. Weinblatt, MD

Professor of Medicine Harvard Medical School Brigham and Women's Hospital Boston, MA, USA 

Students, residents, and fellows interested in learning about the rheumatic diseases are faced with the daunting challenge of trying to integrate learning about a multitude of fascinating and diverse clinical disorders with an ever-expanding and complex body of basic science.

This need encapsulates the principal rationale for the major changes in the 13th edition of The Primer on the Rheumatic Diseases. Although the first part of all recent editions of The Primer have summarized succinctly the physiology of tissues and cells that mediate inflammation and musculoskeletal disease, preparation of the new edition resulted in the identification of two major problems with this "triedand-true" formula. First, for readers who really wished to understand the molecular basis of rheumatic disease to the depth that would facilitate laboratory research and improve patient care, the initial chapters no longer provided sufficient detail. Second, for readers seeking an introduction or update within the clinical realm of rheumatic disorders, the first part of The Primer bore virtually no relation to the diseases described so engagingly in the rest of the book. In short, in this era of increasing integration between the basic and clinical sciences, the preliminary Primer chapters were at risk for becoming simply the pages thumbed through quickly to get to the good stuff.

Therefore, in the 13th edition, the clinical descriptions that The Primer has always done best have been augmented by including the clinically relevant basic science components in the same sections. Thus, for each major rheumatic diseasefor example, rheumatoid arthritis, osteoarthritis, systemic lupus erythematosus, and idiopathic inflammatory myopathies - the chapter describing the clinical and epidemiological features is accompanied by another chapter devoted to "Pathology and Pathogenesis." This second chapter incorporates the appropriate (and updated) elements from previous Primer chapters entitled "Synovium," "Articular Cartilage," "The Complement System," and "Muscle" that are essential to understanding a particular disease today.

Moreover, this fundamental change in the contents is only the beginning of the improvements to the 13 th edition. Other changes include:

- New chapters on "Clinical Immunology" and "Applied Genetics" designed to heighten the translational nature of the book.

- Color figures that are particularly important for depicting cutaneous findings and histopathology.

- An expanded chapter on the cutaneous manifestations of disease, emphasizing the types of disorders rheumatologists often see in consultation.

- A section devoted entirely to juvenile inflammatory arthritis, with individual chapters on "Clinical Features," "Pathology and Pathogenesis," "Treatment and Assessment," and "Special Considerations."

- Separate chapters on ankylosing spondylitis and the reactive and enteropathic arthropathies, once lumped together (with psoriatic arthritis) as "seronegative spondyloarthopathies." 
- A tripling of the text devoted to psoriatic arthritis, an acknowledgement of the substantial treatment advances in that disorder.

- Individual chapters (and more than doubling of the text) to the metabolic and inflammatory myopathies, once included in the same chapter.

- Reorganization of the vasculitis section along more rational and all-inclusive lines, with a chapter entitled "ANCA-Associated Vasculitis" that addresses together Wegener's granulomatosis, microscopic polyangiitis, and the ChurgStrauss syndrome, disorders with striking similarities but important contrasts.

- Now entering its eighth decade, The Primer has rejected strongly the notion that "If it ain't broke, don't fix it." In view of the recent remarkable strides in understanding and treating rheumatic disease, students, trainees, and practicing clinicians all need a standard textbook that can change with the times and reflect these advances. The Primer continues to fill that need. Read, learn, and enjoy.

John H. Klippel, MD

John H. Stone, $M D, M P H$

Leslie J. Crofford, $M D$

Patience H. White, MD, MA 
Foreword by Michael E. Weinblatt $\ldots \ldots \ldots \ldots \ldots \ldots \ldots$ v

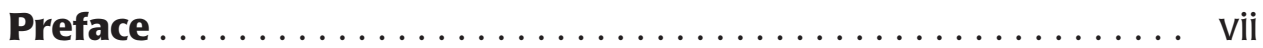

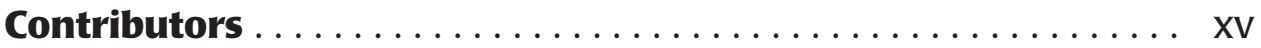

1. Public Health and Arthritis: A Growing Imperative . . . . . 1 Patience H. White and Rowland W. Chang

2. Evaluation of the Patient $\ldots \ldots \ldots \ldots \ldots \ldots \ldots \ldots$

A. History and Physical Examination $\ldots \ldots \ldots \ldots \ldots$

David B. Robinson and Hani S. El-Gabalawy

B. Laboratory Assessment $\ldots \ldots \ldots \ldots \ldots \ldots \ldots \ldots$

Kerstin Morehead

C. Arthrocentesis, Synovial Fluid Analysis,

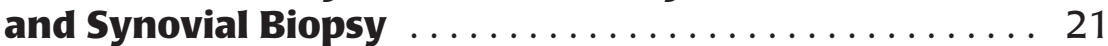

KeNNETH H. Fye

D. Imaging of Rheumatologic Diseases $\ldots \ldots \ldots \ldots \ldots$

William W. Scott, Jr., William J. Didie, AND LAURA M. FAYAD

3. Musculoskeletal Signs and Symptoms $\ldots \ldots \ldots \ldots$. . . 42

A. Monarticular Joint Disease $\ldots \ldots \ldots \ldots \ldots \ldots \ldots \ldots$

H. Ralph Schumacher and Lan X. Chen

B. Polyarticular Joint Disease $\ldots \ldots \ldots \ldots \ldots \ldots \ldots \ldots$

STERLING West

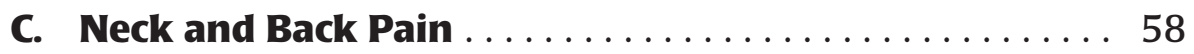

DAVID BORENSTEIN

D. Regional Rheumatic Pain Syndromes . . . . . . . . . 68 Joseph J. Biundo, JR.

E. The Fibromyalgia Syndrome $\ldots \ldots \ldots \ldots \ldots \ldots$ Dina Dadabhoy and Daniel J. Clauw

4. Molecular and Cellular Basis of Immunity

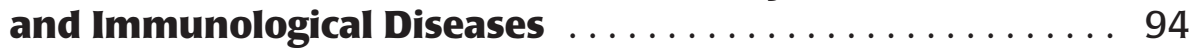

Kevin Elias, Richard Siegel, and John J. O'Shea

James Kelley and Robert P. Kimberly

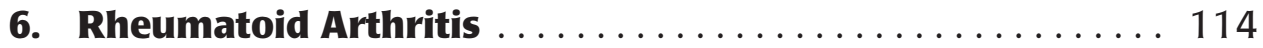

A. Clinical and Laboratory Manifestations $\ldots \ldots \ldots \ldots .114$

Christopher V. Tehlirian and Joan M. Bathon 
B. Epidemiology, Pathology, and Pathogenesis . . . . . . . 122 Jean-Marc Waldburger and Gary S. Firestein

C. Treatment and Assessment

Alyce M. Oliver and E. William St. Clair

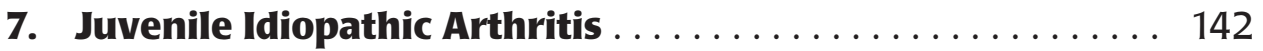

A. Clinical Features . . . . . . . . . . . . . . . . . . . 142

Daniel J. Lovell

B. Pathology and Pathogenesis . . . . . . . . . . . 149

Patricia Woo

C. Treatment and Assessment . . . . . . . . . . . 154

Philip J. Hashres and Ronald M. LaXer

D. Special Considerations . . . . . . . . . . . . . . . 163

Carol B. Lindsley

8. Psoriatic Arthritis $\ldots \ldots \ldots \ldots \ldots \ldots \ldots \ldots \ldots \ldots \ldots \ldots \ldots \ldots \ldots$

A. Clinical Features $\ldots \ldots \ldots \ldots \ldots \ldots \ldots \ldots \ldots \ldots$

Dafna D. Gladman

B. Pathology and Pathogenesis $\ldots \ldots \ldots \ldots \ldots \ldots \ldots$

Christopher Ritchlin

C. Treatment and Assessment . . . . . . . . . . . . . 185

Philip J. MeAse

9. Ankylosing Spondylitis . . . . . . . . . . . . . . . 193

A. Clinical Features $\ldots \ldots \ldots \ldots \ldots \ldots \ldots \ldots \ldots \ldots$

DÉSIRÉE VAN DER HeIJde

B. Pathology and Pathogenesis $\ldots \ldots \ldots \ldots \ldots$

Juergen Braun

C. Treatment and Assessment ............. 209 John C. Davis, JR.

10. Reactive and Enteropathic Arthritis $\ldots \ldots \ldots \ldots 217$

Robert D. InMAN

11. Osteoarthritis $\ldots \ldots \ldots \ldots \ldots \ldots \ldots \ldots \ldots \ldots \ldots \ldots \ldots \ldots$

A. Clinical Features . . . . . . . . . . . . . . . . . . . . . . . . 224

PAUl DiePPE

B. Pathology and Pathogenesis . . . . . . . . . . . . 229

Francis Berenbaum

C. Treatment ......................... 235

LEENA Sharma

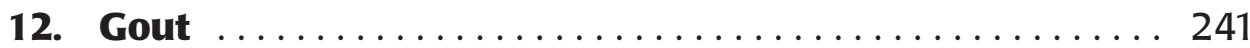

A. Clinical Features . . . . . . . . . . . . . . . . 241

N. LAWRENCE EdWARDS 

B. Epidemiology, Pathology, and
Pathogenesis .......................... 250
HYON K. CHOI

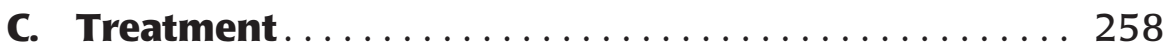
Robert A. Terkeltaub

13. Calcium Pyrophosphate Dihydrate, Hydroxyapatite, and Miscellaneous Crystals . . . . . . . . 263

Geraldine McCARThy

14. Infectious Disorders $\ldots \ldots \ldots \ldots \ldots \ldots \ldots \ldots \ldots \ldots \ldots$

A. Septic Arthritis $\ldots \ldots \ldots \ldots \ldots \ldots \ldots \ldots \ldots \ldots \ldots \ldots$

GeORge Ho, Jr.

B. Viral Arthritis $\ldots \ldots \ldots \ldots \ldots \ldots \ldots \ldots \ldots \ldots \ldots \ldots$

Leonard H. Calabrese

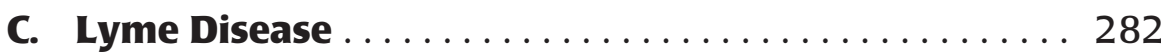

LINDA K. BOCKENSTEDT

D. Mycobacterial, Fungal, and Parasitic

Arthritis ........................... 290

STEVEN R. YTterberg

E. Rheumatic Fever . . . . . . . . . . . . . . . . . . . . . . . 297

Stanford Shulman and Preeti Jaggi

15. Systemic Lupus Erythematosus . . . . . . . . . . . . . . 303

A. Clinical and Laboratory Features . . . . . . . . . . 303 JILL P. BUYON

B. Epidemiology, Pathology, and Pathogenesis ... . . . . . . . . . . . . . . . . . . . 319

DAVID S. PISETSKY

C. Treatment and Assessment . . . . . . . . . . . . . . . . 327

Susan Manzi AND Amy H. KaO

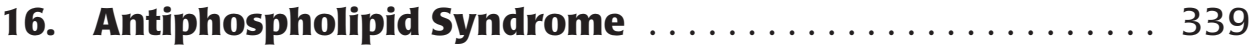
Michelle Petri

17. Systemic Sclerosis . . . . . . . . . . . . . . . . 343

A. Clinical Features $\ldots \ldots \ldots \ldots \ldots \ldots \ldots \ldots \ldots \ldots, \ldots \ldots$

Maureen D. Mayes

B. Epidemiology, Pathology, and Pathogenesis $\ldots \ldots \ldots 351$ JOHN VARGA

C. Treatment and Assessment . . . . . . . . . . . . . 359

Maya H. Buch and James R. Seibold

18. Idiopathic Inflammatory Myopathies $\ldots \ldots \ldots \ldots 36$

A. Clinical Features $\ldots \ldots \ldots \ldots \ldots \ldots \ldots \ldots \ldots \ldots \ldots$

ROBERT L. WORTMANN 


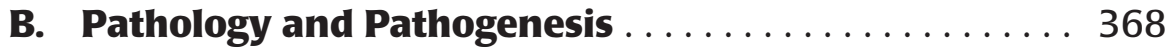

Lisa G. Rider and Frederick W. Miller

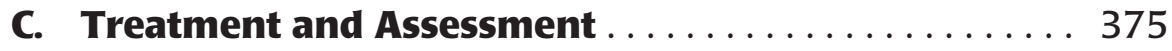
Chester V. Oddis

19. Metabolic Myopathies

Alan N. Baer

20. Sjögren's Syndrome

Troy Daniels

21. Vasculitides .

A. Giant Cell Arteritis, Polymyalgia Rheumatica, and Takayasu's Arteritis

Cornelia M. Weyand and Jörg J. Goronzy

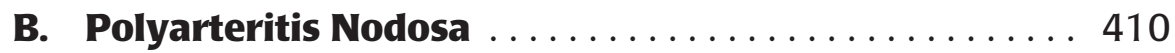

KeIth T. RotT

C. The Antineutrophil Cytoplasmic

Antibody-Associated Vasculitides: Wegener's

Granulomatosis, Microscopic Polyangiitis, and the Churg-Strauss Syndrome

JoHN H. STONE

D. Immune Complex-Mediated Vasculitis

Philip SeO

E. Miscellaneous Vasculitis (Behçet's Disease, Primary Angiitis of the Central Nervous System, Cogan's Syndrome, and Erythema Elevatum Diutinum)

Kenneth T. Calamia and Carlo Salvarani

F. Kawasaki's Disease

BARRY L. MYONES

22. Relapsing Polychondritis

Harvinder S. Luthra

23. Adult-Onset Still's Disease

John M. EsDAILE

24. Periodic Syndromes . . . . . . . . . . . . . . . . 460

John G. Ryan and Daniel L. Kastner

25. Less Common Arthropathies $\ldots \ldots \ldots \ldots \ldots \ldots \ldots$

A. Hematologic and Malignant Disorders . . . . . . . 470 Adel G. Fam

B. Rheumatic Disease and Endocrinopathies . . . . . . 479 Peter A. Merkel

C. Hyperlipoproteinemia and Arthritis ROBERT F. SPIERA 
D. Neuropathic Arthropathy $\ldots \ldots \ldots \ldots \ldots \ldots \ldots 8$ AnN K. Rosenthal

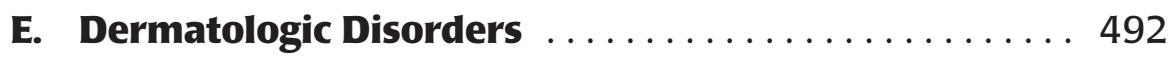
JefFrey P. CALlen

F. Hypertrophic Osteoarthropathy . . . . . . . . . . . . . 504 Manuel Martinez-Lavin

26. Complex Regional Pain Syndrome . . . . . . . . . . . . . . 509 GEOFFREy LiTTLEJOHN

27. Sarcoidosis ........................ 514 Edward S. Chen

28. Storage and Deposition Diseases $\ldots \ldots \ldots \ldots 23$ Duncan A. Gordon

29. The Amyloidoses . . . . . . . . . . . . . . . . . . 533 Pasha Sarraf and Jonathan Kay

30. Neoplasms of the Joint . . . . . . . . . . . . . . . . 543 Andrew J. Cooper, James D. Reeves, and Sean P. Scully

31. Heritable Disorders of Connective Tissue . . . . . . . . . . . 549 Reed Edwin Pyeritz

32. Bone and Joint Dysplasias $\ldots \ldots \ldots \ldots \ldots \ldots$. . . . . 559 William A. Horton

33. Osteonecrosis . . . . . . . . . . . . . . . . 565 Thorsten M. Seyler, David Marker, and Michael A. Mont

34. Paget's Disease of Bone $\ldots \ldots \ldots \ldots \ldots \ldots \ldots \ldots \ldots$ Roy D. Altman

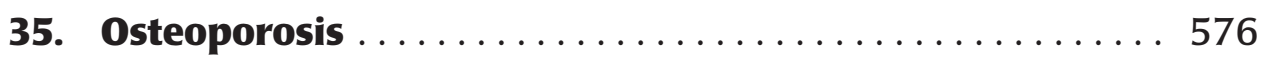
A. Epidemiology and Clinical Assessment . . . . . . . 576 Kenneth G. SaAg
B. Pathology and Pathophysiology . . . . . . . . . 584 Philip SAMBrooK
C. Treatment of Postmenopausal Osteoporosis . . . . . . 592 Nelson B. WatTs

36. Rehabilitation of Patients with Rheumatic

Diseases . . . . . . . . . . . . . . . . . . . . . . 599

Thomas D. BeARdMore

37. Psychosocial Factors in Arthritis . . . . . . . . . . 609

Alex Zautra and Denise Kruszewski

38. Self-Management Strategies $\ldots \ldots \ldots \ldots \ldots \ldots \ldots \ldots$ TEREsa J. BRADY

39. Pain Management $\ldots \ldots \ldots \ldots \ldots \ldots \ldots \ldots \ldots \ldots \ldots \ldots$ 
40. Therapeutic Injections of Joints and Soft Tissues . . . . . 628 Juan J. Canoso

41. Nonsteroidal Anti-Inflammatory Drugs . . . . . . . . . . 634 LESLIE J. CROFFoRD

42. Glucocorticoids 644 Frank Buttgereit and Gerd-RÜDIGER Burmester

43. Operative Treatment of Arthritis 651

Joseph A. Buckwalter AND W. Timothy Ballard

44. Complementary and Alternative Therapies 664

Erin L. Arnold and William J. Arnold

Appendix I. Criteria for the Classification and Diagnosis of the Rheumatic Diseases . . . . . . . . . . . . . 669

Appendix II. Guidelines for the Management of Rheumatic Diseases 683

Appendix III. Supplement and Vitamin and Mineral Guide

Index 703 
Roy D. Altman, MD

Professor, Deparment of Medicine/Rheumatology and Immunology, University of California, Los Angeles, Los Angeles, CA, USA

Erin L. Arnold, MD

Partner/Rheumatologist, Illinois Bone and Joint Institute, The Center for Arthritis and Osteoporosis, Morton Grove, IL, USA

William J. Arnold, MD

Partner/Rheumatologist, Illinois Bone and Joint Institute, The Center for Arthritis and Osteoporosis, Morton Grove, IL, USA

\section{Alan N. Baer, MD}

Associate Professor, Department of Medicine, Chief, Section of Rheumatology, University at Buffalo, State University of New York, Buffalo, NY, USA

W. Timothy Ballard, MD

Director, Joint Replacement Center, Department of Orthopaedics, Memorial Hospital, Chattanooga, TN, USA

Joan M. Bathon, MD

Professor, Department of Medicine, Director, Johns Hopkins Arthritis Center, Johns Hopkins University School of Medicine, Baltimore, MD, USA

Thomas D. Beardmore, MD, FACP, FACR

Chief, Department of Rheumatology, Rancho Los Amigos National Rehabilitation Center, Downey, CA; Professor, Department of Medicine, Keck School of Medicine, The University of Southern California, Los Angeles, CA, USA

Francis Berenbaum, MD, PhD

Professor, Department of Rheumatology, Saint-Antoine Hospital; University Pierre \& Marie Curie, Paris, France

Joseph J. Biundo, Jr., MD

Clinical Professor, Department of Medicine, Tulane University School of Medicine, Kenner, LA, USA

Linda K. Bockenstedt, MD

Professor, Department of Internal Medicine, Yale University School of Medicine, New Haven, CT, USA

David Borenstein, MD

Clinical Professor of Medicine, The George Washington University Medical Center; Arthritis and Rheumatism Associates, Washington, DC, USA
Teresa J. Brady, PhD

Senior Behavioral Scientist, Arthritis Program, Centers for Disease Control and Prevention, Atlanta, GA, USA

Juergen Braun, MD

Professor, Department of Rheumatology, Rheumazentrum Ruhrgebiet, Herne, Germany

Maya H. Buch, MBchB, MRCP

Clinical Lecturer and Research Fellow, University of Michigan Scleroderma Program, University of Michigan Health System, Ann Arbor, MI, USA; Academic Unit of Musculoskeletal Disease, University of Leeds, UK

Joseph A. Buckwalter, MS, MD

Professor and Head, Orthopedic Surgery, Department of Orthopaedics and Rehabilitation, University of Iowa, Iowa City, IA, USA

Gerd-Rüdiger Burmester, MD

Professor, Department of Rheumatology and Clinical Immunology, Charité University Hospital, Berlin, Germany

Frank Buttgereit, MD

Professor, Department of Rheumatology and Clinical Immunology, Charité University Hospital, Berlin, Germany

Jill P. Buyon, MD

Professor, Department of Medicine, Division of Rheumatology, New York University School of Medicine, New York, NY; Director, Lupus Clinic, New York University Hospital for Joint Diseases, New York, NY, USA

Leonard H. Calabrese, DO

Professor, Department of Rheumatic and Immunologic Diseases, Cleveland Clinic Lerner College of Medicine of Case Western Reserve University, Cleveland Clinic Foundation, Cleveland, OH, USA

Kenneth T. Calamia, MD

Associate Professor, Department of Medicine, Division of Rheumatology, Mayo Clinic College of Medicine, Jacksonville, FL, USA

Jeffrey P. Callen, MD

Professor, Department of Medicine (Dermatology); Chief, Division of Dermatology, University of Louisville School of Medicine, Louisville, KY, USA 
Juan J. Canoso, MD, FACP, MACR

Attending, American British Cowdray Medical Center, Mexico City, Mexico

Rowland W. Chang, MD, MPH

Professor of Preventive Medicine, Medicine, and Physical Medicine and Rehabilitation; Director, Program in Public Health, Northwestern University, Feinberg School of Medicine, Chicago, IL, USA

Edward S. Chen, MD

Assistant Professor, Department of Medicine, Division of Pulmonary and Critical Care Medicine, Johns Hopkins University School of Medicine, Baltimore, MD, USA

Lan X. Chen, MD, PhD

Clinical Assistant Professor, Department of Medicine/ Rheumatology, University of Pennsylvania, Philadelphia, PA, USA

Hyon K. Choi, MD, MPH, DrPH, FRCPC

Associate Professor of Medicine and Mary Pack Arthritis Society Chair in Rheumatology, Department of Medicine, Division of Rheumatology, The University of British Columbia, Vancouver, British Columbia, Canada

Daniel J. Clauw, MD

Professor, Department of Internal Medicine, Division of Rheumatology, University of Michigan, Ann Arbor, MI, USA

Andrew J. Cooper, MD

Resident, Department of Orthopaedic Surgery, University of Miami, Miami, FL, USA

Leslie J. Crofford, MD

Gloria W. Singletary Professor of Internal Medicine, Chief, Division of Rheumatology \& Women's Health, University of Kentucky, Lexington, KY, USA

Dina Dadabhoy, MD

Clinical Lecturer, Department of Internal Medicine, Division of Rheumatology, University of Michigan, Ann Arbor, MI, USA

Troy Daniels, DDS, MS

Professor, Schools of Dentistry and Medicine, University of California, San Francisco, San Francisco, CA, USA

John C. Davis, Jr., MD, MPH

Associate Professor, Department of Medicine, Division of Rheumatology, University of California San Francisco, San Francisco, CA, USA

William J. Didie, MD

Fellow, Musculoskeletal Imaging, Department of Radiology, Johns Hopkins University, Baltimore, MD, USA

Paul Dieppe, MD

Professor, Department of Social Medicine, University of Bristol, Bristol, UK
N. Lawrence Edwards, MD

Professor and Vice Chairman, Department of Medicine, University of Florida, Gainesville, FL, USA

Hani S. El-Gabalawy, MD, FRCPC

Professor, Department of Medicine, Arthritis Centre, University of Manitoba, Winnipeg, Manitoba, Canada

Kevin Elias, MD

Howard Hughes Medical Institute-National Institute of Health Research Scholar, Lymphocyte Cell Biology Section, National Institute of Arthritis, Musculoskeletal, and Skin Diseases, Bethesda, MD, USA

John M. Esdaile, MD, MPH

Scientific Director, Arthritis Research Centre of Canada; Professor, University of British Columbia, Vancouver, British Columbia, Canada

Adel G. Fam, MD, FRCP(C), FACP

Emeritus Professor of Medicine, Department of Medicine, Division of Rheumatology, Sunnybrook \& Women's College Health Sciences Centre, University of Toronto, Toronto, Ontario, Canada

Laura M. Fayad, MD

Assistant Professor, The Russell H. Morgan Department of Radiology and Radiological Science, Johns Hopkins University School of Medicine, Baltimore, MD, USA

Gary S. Firestein, MD

Professor, Department of Medicine, Chief, Division of Rheumatology, Allergy and Immunology, University of California San Diego, School of Medicine, La Jolla, CA, USA

Kenneth H. Fye, MD

Clinical Professor, Department of Medicine, University of California, San Francisco, San Francisco, CA, USA

Dafna D. Gladman, MD, FRCPC

Professor, Department of Medicine/Rheumatology, University of Toronto; Senior Scientist, Toronto Western Research Institute; Director, Psoriatic Arthritis Program, University Health Network, Toronto, Canada

Duncan A. Gordon, MD, FRCPC, MACR

Professor, Department of Medicine, University of Toronto; Rheumatologist, University Health Network, Toronto Western Hospital, Toronto, Ontario, Canada

Jörg J. Goronzy, MD

Co-Director, Department of Medicine, Kathleen B. and Mason I. Lowance Center for Human Immunology, Emory University School of Medicine, Atlanta, GA, USA

Philip J. Hashkes, MD, MSc

Head, Section of Pediatric Rheumatology, Department of Rheumatic Diseases, Cleveland Clinic Foundation, Cleveland, $\mathrm{OH}, \mathrm{USA}$ 
George Ho, Jr., MD

Professor, Department of Internal Medicine, Division of Rheumatology, Brody School of Medicine at East Carolina University, Greenville, NC, USA

William A. Horton, MD

Director, Research Center/Molecular and Medical Genetics, Shriners Hospital for Children; Professor, Oregon Health and Science University, Portland, OR, USA

Robert D. Inman, MD

Professor, Department of Medicine, Division of Rheumatology, University of Toronto, Toronto Western Hospital, Toronto, Ontario, Canada

Preeti Jaggi, MD

Assistant Professor, Department of Infectious Diseases, Department of Pediatrics, Ohio State University, Columbus, $\mathrm{OH}$, USA

Amy H. Kao, MD, MPH

Assistant Professor, Department of Medicine, Division of Rheumatology and Clinical Immunology, University of Pittsburgh School of Medicine, Pittsburgh, PA, USA

Daniel L. Kastner, MD, PhD

Chief, Genetics and Genomics Branch; Clinical Director and Director of Translational Research, National Institute of Arthritis and Musculoskeletal and Skin Diseases, Bethesda, MD, USA

Jonathan Kay, MD

Associate Clinical Professor, Department of Medicine, Harvard Medical School; Director of Clinical Trials, Rheumatology Unit, Massachusetts General Hospital, Boston, MA, USA

James Kelley, PhD

Postdoctoral Fellow, Department of Medicine, Division of Clinical Immunology and Rheumatology, University of Alabama at Birmingham, Birmingham, AL, USA

Robert P. Kimberly, MD

Howard L. Holley Professor of Medicine and Director, Division of Clinical Immunology and Rheumatology, Senior Associate Dean for Research, Department of Medicine, University of Alabama at Birmingham, Birmingham, AL, USA

John H. Klippel, MD

President and CEO, Arthritis Foundation, Atlanta, GA, USA

Denise Kruszewski, MS

Graduate Student/Research Assistant, Department of Psychology, Arizona State University, Tempe, AZ, USA

Ronald M. Laxer, MD, FRCPC

Vice President, Education and Quality, The Hospital for Sick Children; Professor, Department of Pediatrics and Medicine, The University of Toronto, Toronto, Ontario, Canada
Carol B. Lindsley, MD

Professor, Department of Pediatrics, Director of Pediatric Rheumatology, University of Kansas Medical Center, Kansas City, KS, USA

Geoffrey Littlejohn, MD, MPH, MBBS[Hon], FRACP, $\operatorname{FRCP}($ Edin $)$

Director of Rheumatology and Associate Professor of Medicine, Department of Medicine, Monash University at Monash Medical Centre, Melbourne, Australia

Daniel J. Lovell, MD, MPH

Joseph Levinson Professor of Pediatrics, Division of Rheumatology, Cincinnati Children's Hospital Medical Center, Cincinnati, OH, USA

Harvinder S. Luthra, MD

John Finn Professor of Medicine, Department of Rheumatology, Mayo Clinic College of Medicine, Rochester, MN, USA

Susan Manzi, MD, MPH

Associate Professor, Department of Medicine, Division of Rheumatology and Clinical Immunology, University of Pittsburgh School of Medicine, University of Pittsburgh Graduate School of Public Health, Pittsburgh, PA, USA

David Marker, BS

Medical Student, Rubin Institute for Advanced Orthopedics, Sinai Hospital of Baltimore, Baltimore, MD, USA

Manuel Martinez-Lavin, MD

Chief, Department of Rheumatology, National Institute of Cardiology, Mexico, DF, Mexico

Maureen D. Mayes, MD, MPH

Professor, Department of Internal Medicine, Division of Rheumatology and Immunogenetics, University of TexasHouston Medical School, Houston, TX, USA

Geraldine McCarthy, MD, FRCPI

Associate Professor/Consultant Rheumatologist, Division of Rheumatology, Department of Medicine, University College Dublin, Dublin/Mater Misericordiae University Hospital, Dublin, Ireland

Philip J. Mease, MD

Head, Seattle Rheumatology Associates; Chief, Division of Rheumatology Research, Swedish Medical Center; Clinical Professor, University of Washington School of Medicine, Seattle, WA, USA

Peter A. Merkel, MD, MPH

Associate Professor, Department of Medicine, Section of Rheumatology, Boston University School of Medicine, Boston, MA, USA

Frederick W. Miller, MD, PhD

Chief, Environmental Autoimmunity Group, Office of Clinical Research, National Institute of Environmental Health Sciences, National Institutes of Health, Bethesda, MD, USA 
Michael A. Mont, MD

Director, Rubin Institute for Advanced Orthopedics, Sinai Hospital of Baltimore, Baltimore, MD, USA

Kerstin Morehead, MD

Assistant Clinical Professor, Department of Medicine, Division of Rheumatology, University of California, San Francisco, San Francisco, CA, USA

Barry L. Myones, MD

Associate Professor, Pediatric Rheumatology Center, Baylor College of Medicine/Texas Children's Hospital, Houston, TX, USA

Chester V. Oddis, MD

Professor, Department of Medicine, Division of Rheumatology and Clinical Immunology, University of Pittsburgh School of Medicine, Pittsburgh, PA, USA

Alyce M. Oliver, MD, PhD

Fellow in Rheumatology, Department of Medicine, Division of Rheumatology and Immunology, Duke University Medical Center, Durham, NC, USA

John J. O'Shea, MD

Scientific Director, National Institute of Arthritis and Musculoskeletal and Skin Diseases; Chief, Molecular Immunology and Inflammation Branch; Chief, Lymphocyte Cell Biology Section, National Institutes of Health, Bethesda, MD, USA

Michelle Petri, MD, MPH

Professor, Department of Medicine, Johns Hopkins University School of Medicine, Baltimore, MD, USA

David S. Pisetsky, MD, PhD

Chief, Department of Medicine, Division of Rheumatology and Immunology, Duke University School of Medicine, Durham, NC, USA

Reed Edwin Pyeritz, MD, PhD

Professor, Department of Medicine and Genetics, Hospital of the University of Pennsylvania, Philadelphia, PA, USA

James D. Reeves, MD

Resident, Department of Orthopaedic Surgery, University of Miami, Miami, FL, USA

Lisa G. Rider, MD

Deputy Chief, Environmental Autoimmunity Group, Office of Clinical Research, National Institute of Environmental Health Sciences, National Institutes of Health, Clinical Research Center, Bethesda, MD, USA

Christopher Ritchlin, MD

Associate Professor, Department of Medicine, Division of Allergy, Immunology and Rheumatology, University of Rochester Medical Center, Rochester, NY, USA

David B. Robinson, MD, MSc, FRCPC

Associate Professor, Department of Medicine, Arthritis Centre, University of Manitoba, Winnipeg, Manitoba, Canada
Ann K. Rosenthal, MD

Professor, Department of Medicine, Division of Rheumatology, Medical College of Wisconsin/Zablocki VA Medical Center, Milwaukee, WI, USA

Keith T. Rott, MD, PhD

Assistant Professor, Department of Medicine, Division of Rheumatology, Emory University School of Medicine, Atlanta, GA, USA

John G. Ryan, MB, MRCPI

Clinical Fellow, Genetics and Genomics Branch, National Institute of Arthritis and Musculoskeletal and Skin Diseases, National Institutes of Health, Bethesda, MD, USA

Kenneth G. Saag, MD, MSc

Associate Professor, Director, Center for Education and Research on Therapeutics of Musculoskeletal Disorders, Division of Clinical Immunology and Rheumatology, University of Alabama at Birmingham, Birmingham, AL, USA

Carlo Salvarani, MD

Director, Division of Rheumatology, Hospital S. Maria Nuova, Reggio Emilia, Italy

Philip Sambrook, MD, FRACP

Professor, Department of Rheumatology, University of Sydney, Sydney, NSW Australia

Pasha Sarraf, MD, PhD

Fellow, Department of Medicine, Division of Rheumatology, Allergy and Immunology, Massachusetts General Hospital, Boston, MA, USA

H. Ralph Schumacher, MD

Professor, Department of Medicine/Rheumatology, University of Pennsylvania; VA Medical Center, Philadelphia, PA, USA

William W. Scott, Jr., MD

Associate Professor, The Russell H. Morgan Department of Radiology and Radiological Science, Johns Hopkins University School of Medicine, Baltimore, MD, USA

Sean P. Scully, MD, PhD

Professor, Department of Orthopaedics, Miller School of Medicine, University of Miami, Miami, FL, USA

James R. Seibold, MD

Professor, Department of Internal Medicine/Rheumatology, Director, University of Michigan Scleroderma Program, University of Michigan Health System, Ann Arbor, MI, USA

Philip Seo, MD, MHS

Co-Director, Johns Hopkins Vasculitis Center, Division of Rheumatology, Johns Hopkins University School of Medicine, Baltimore, MD, USA

Thorsten M. Seyler, MD

Center for Joint Preservation and Reconstruction, Rubin Institute for Advanced Orthopedics, Sinai Hospital of Baltimore, Baltimore, MD, USA 
Leena Sharma, MD

Professor, Department of Internal Medicine, Division of Rheumatology, Feinberg School of Medicine at Northwestern University, Chicago, IL, USA

Stanford Shulman, MD

Chief, Department of Infectious Diseases; Professor, Department of Pediatrics, Northwestern University Feinberg School of Medicine/The Children's Memorial Hospital, Chicago, IL, USA

Richard Siegel, MD, PhD

Principal Investigator, Immunoregulation Group, National Institute of Arthritis and Musculoskeletal and Skin Diseases, National Institutes of Health, Bethesda, MD, USA

Robert F. Spiera, MD

Adjunct Clinical Instructor, Department of Medicine/ Rheumatology, Mount Sinai School of Medicine, New York, NY, USA

E. William St. Clair, MD

Professor, Department of Medicine, Division of Rheumatology and Immunology, Duke University Medical Center, Durham, NC, USA

John H. Stone, MD, MPH

Associate Physician, Massachusetts General Hospital; Deputy Editor for Rheumatology, UpToDate, Boston, MA, USA

Christopher V. Tehlirian, MD

Post-Doctoral Fellow, Department of Medicine, Division of Clinical and Molecular Rheumatology, Johns Hopkins University School of Medicine, Baltimore, MD, USA

Robert A. Terkeltaub, MD

Chief, Rheumatology Section, Department of Medicine, Veterans Affairs Medical Center San Diego; Professor, Department of Medicine, University of California San Diego School of Medicine, San Diego, CA, USA

Désirée Van der Heijde, MD, PhD

Professor, Department of Rheumatology, University Hospital Maastricht, The Netherlands

John Varga, MD

Gallagher Professor of Medicine, Department of Medicine, Division of Rheumatology, Northwestern University Feinberg School of Medicine, Chicago, IL, USA
Jean-Marc Waldburger, MD, PhD

Post-Doctoral Scholar, Department of Medicine, Division of Rheumatology, Allergy, and Immunology, University of California San Diego School of Medicine, La Jolla, CA, USA

Nelson B. Watts, MD

Professor, Department of Internal Medicine, University of Cincinnati College of Medicine, Cincinnati, OH, USA

Sterling West, MD

Professor, Department of Rheumatology, University of Colorado Health Sciences Center, Denver, CO, USA

Cornelia M. Weyand, MD

Co-Director, Kathleen B. and Mason I. Lowance Center for Human Immunology, Department of Medicine, Emory University School of Medicine, Atlanta, GA, USA

Patience H. White, MD, MA

Chief Public Health Officer, Arthritis Foundation, Atlanta, GA, USA

John B. Winfield, MD

Smith Distinguished Professor of Medicine Emeritus, Department of Medicine, University of North Carolina, Chapel Hill, NC, USA

Patricia Woo, BSc, MBBS, PhD, MRCP, FRCP, CBE

Professor, Department of Immunology and Molecular Pathology, University College London, London, UK

Robert L. Wortmann, MD, FACP, FACR

Professor and C. S. Lewis, Jr., MD Chair of Medicine, Department of Internal Medicine, The University of Oklahoma College of Medicine, Tulsa, OK, USA

Steven R. Ytterberg, MD

Associate Professor, Department of Medicine, Division of Rheumatology, Mayo Clinic College of Medicine, Rochester, MN, USA

Alex Zautra, PhD

Foundation Professor, Department of Psychology, Arizona State University, Tempe, AZ, USA 